\title{
Treatment of ano-rectal gonorrhoea with ampicillin
}

\author{
J. JOHN AND F. J. G. JEFFERISS \\ St. Mary's Hospital, London, W.2
}

It has been observed that there is a high incidence of treatment failure in cases of ano-rectal gonorrhoea treated by the time-honoured standard methods. At this hospital urethral gonorrhoea has responded well for many years to one injection only of $1 \cdot 2 \mathrm{~m}$.u. procaine penicillin given intramuscularly; but similar treatment for an ano-rectal infection with gonococci has given very poor results. Treatment of the latter by daily injections of procaine penicillin for even 4 to 5 days was also often unsatisfactory, but when tetracycline, ampicillin, or 'Septrin' (trimethoprim plus sulphamethoxazole) was given for the same period, the success rate appeared to be higher. A possible reason for this is that, in a rectal infection, some of the gonococcal pus becomes caught up in the faeces and remains there to re-infect the rectal mucosa when the serum penicillin level falls below a bacteriocidal or bacteriostatic level. This would happen 15 to $18 \mathrm{hrs}$ after a single injection of procaine penicillin and would leave a gap of 6 to $9 \mathrm{hrs}$ in which the rectum could be re-infected from the faeces even if a further injection were given $24 \mathrm{hrs}$ after the first one. However, if a continuous bacteriostatic or bacteriocidal level is kept up for several days by giving tetracyline, ampicillin, or 'Septrin' by mouth 6-hrly, there is a good chance that the infected faeces may have been passed out of the body before the blood level has dropped sufficiently for the mucous membrane to be re-infected.

\section{Material and methods}

The series under review consists of 112 patients with ano-rectal gonorrhoea treated at St. Mary's Hospital, London, during 1971 and 1972. All were given ampicillin capsules, $250 \mathrm{mg}$. four times a day for 5 days. Nine defaulted from the follow-up, leaving 103 for assessment. Diagnosis was based on finding Gram-negative intracellular diplococci in stained smears taken from the anorectal region by proctoscopy and confirmed by isolation in culture. After treatment, tests of cure were carried out on all 103 patients on at least two occasions during the following 2 to 4 weeks, by examination of Gram-stained anorectal smears and by culture.

Received for publication October 16, 1972

\section{Results}

Of the 103 cases followed, six (5.8 per cent.) showed persistent gonococci, by both Gram-stained smears and culture. All six denied further exposure to infection and were treated successfully by either tetracycline $500 \mathrm{mg}$. four times daily for 5 days or 'Septrin' for the same period. No toxic effects from ampicillin were observed.

\section{Discussion}

The results of treating ano-rectal gonorrhoea by various methods have been described by several authors over the last 6 years. A single injection of procaine penicillin 600,000 units produced a failure rate of 43 per cent. (Scott and Stone, 1966), whereas a single injection of procaine penicillin $1.8 \mathrm{~m}$.u. gave a failure rate of $27 \cdot 1$ per cent. (Fluker and Boulton Hewitt, 1970). The latter authors obtained a failure rate of 15.5 per cent. after a single injection of 2 g. kanamycin. Waugh (1971) reported a lower failure rate $(12 \cdot 1$ per cent.) using 'Septrin' two tablets twice daily for 7 days. It has been our impression that oral ampicillin, $250 \mathrm{mg}$. four times a day for 5 days, which has been used for 4 years in a large number of cases, has proved to be a most successful treatment. This has been difficult to prove statistically because of the well-known habits of default and promiscuity common in the type of patient infected in this way, but in the 103 cases described above the failure rate was only 5.8 per cent., which confirms our impression of the superiority of ampicillin to other forms of treatment. Procaine penicillin by injection is by far the cheapest of all these methods of treatment, but ampicillin is more economical than 'Septrin' and kanamycin.

It is possible that injections of penicillin $1.2 \mathrm{~m} . \mathrm{u}$. combined with probenecid tablets would give equally good results, but we have not yet had sufficient experience with cases of rectal infection, although urethral gonorrhoea has responded very well indeed to this treatment. 


\section{Summary}

Recent reports of the results of treating ano-rectal gonorrhoea by various methods are noted. 112 patients were given ampicillin $250 \mathrm{mg}$. four times a day for 5 days; nine defaulted and the cure rate in the remainder was 94.2 per cent. Considering the cure rate and the economy of treatment, ampicillin appears to be the most acceptable form of therapy.

\section{References}

Fluker, J. L., and Hewit, A. B. (1970) Brit. f. vener. Dis., 46, 454
Scott, J., and Stone, A. H. (1966) Ibid., 42, 103

WAUGH, M. A. (1971) Ibid., 47, 34

Traitement de la gonococie ano-rectale par l'ampicilline

SOMMAIRE

On mentionne les publications récentes sur les résultats du traitement de la gonococcie ano-rectale par diverses méthodes. 112 malades reçurent quatre fois par jour $250 \mathrm{mg}$ d'ampicilline pendant 5 jours; neuf ne revinrent pas et, pour les autres, le taux de guérison fut de 94,2 pour cent. En considérant le taux de guérison et le coût du traitement, l'ampicilline apparaît comme la forme de traitement la plus appropriée. 